\title{
Динамика мод шепчущей галереи на поверхности оптического волокна вблизи его торца
}

\author{
Д.В. Кудашкин ${ }^{*}$, И.Д. Ватник, Д.В. Чуркин \\ Новосибирский государственный университет \\ *E-mail: d.kudashkin@g.nsu.ru
}

DOI: 10.31868/RFL2020.203-204

Моды шепчущей галереи (МШГ), возбуждаемые на поверхности цилиндрических волоконных микрорезонаторов, и, в частности, на поверхности оптического волокна, могут иметь ненулевую скорость распространения вдоль оси резонатора, которая зависит от вариации эффективного радиуса [1]. Изменением радиуса волокна можно контролировать скорость распространения мод. Так же скорость распространения моды зависит от разности резонансной длины волны микрорезонатора и длины волны, на которой распространяется мода [2]. На базе таких резонаторов могут быть созданы устройства для генерации оптических гребёнок, линии задержки, оптомеханические переключатели и пр.

Актуальной задачей является поиск новых способов управления аксиальным распространением мод. Одним из таких способов может стать использование геометрии волокна, например, торца волокна. Когда излучение в моде шепчущей галереи падает на торец волокна, угол между направлением распространения аксиальной МШГ в (лучевом приближении) и торцом мал. Так как показатель преломления кварцевой оболочки оптического волокна выше, чем показатель преломления воздуха, на торце волокна может произойти полное внутреннее отражение. В нашей работе мы изучили этот процесс отражения МШГ и определили коэффициент отражения.

Для этого в микрорезонатор подавались лазерные импульсы длительностью 0,5 нс с длинами волн, близкими к резонансной длине волны с нулевым аксиальным волновым вектором. Торец микрорезонатора был изготовлен путём скалывания волокна алмазным ножом. Излучение в резонатор заводилось через тейпер - вытянутое с помощью нагрева $\mathrm{CO} 2$ лазером микроволокно. Перетяжка тейпера располагается перпендикулярно микрорезонатору. Для сканирования вдоль оси резонатора использовался второй тейпер, с его помощью была измерена пространственно-временная динамика интенсивности излучения $I(z, t)$.

При импульсном возбуждении исходный волновой пакет делится на несколько импульсов, распространяющихся вдоль оболочки с различными групповыми скоростями: на рис.1а можно различить как минимум два отдельных импульса: первый имеет настолько большую групповую скорость, что временного разрешения осциллографа оказывается недостаточно, чтобы увидеть его отражение. Кажется, что эта часть импульса мгновенно появляется повсюду в резонаторе. Другая часть возбуждения распространяется с конечной скоростью от возбуждающего тейпера, расположенного в точке $\mathrm{z}=-3200$ мкм в направлении торца, а затем отражается от скола волокна в точке $\mathrm{z}=0$ и двигается назад от скола. 

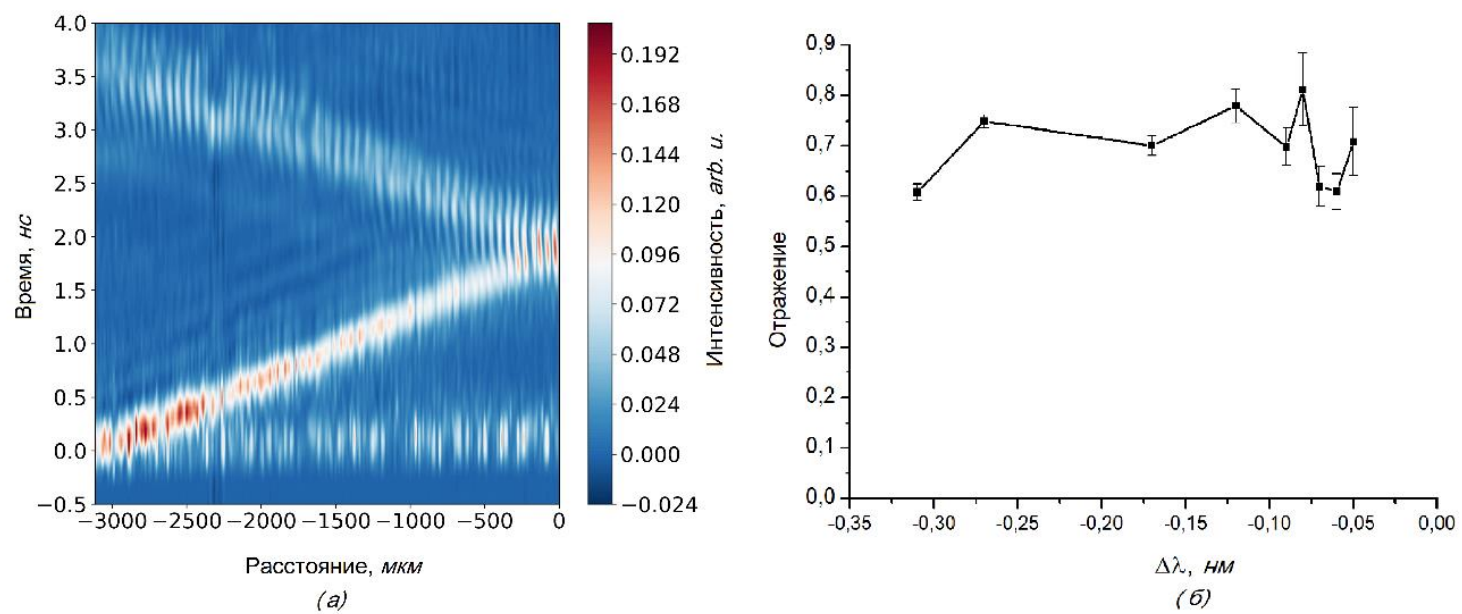

Рис.1. (а) Пространственно-временная динамика МШГ с расщеплением моды после отражения.

(б) Рассчитанное отражение R на торце волокна как функция отстройки длины волны.

На рисунке 16 приведён график зависимости коэффициента отражения от $\Delta \lambda$ - отстройки длины волны импульса от резонансной длины волны моды. Коэффициент вычислялся как отношение суммарной интенсивности падающей и отражённой моды. Для исследуемого образца коэффициент отражения составляет порядка 70\%. Независимость коэффициента отражения $\mathrm{R}$ от $\Delta \lambda$ даёт дополнительную информацию о процессе отражения. Во-первых, это доказывает, что потери при распространении не влияют на оценки отражения. Действительно, можно ожидать, что линейные потери при распространении должны сильно зависеть от длины волны - большие отстройки и большие групповые скорости делают оптический путь моды короче. Это должно уменьшить чистые потери и их вклад в коэффициент отражения, оцененный нашим методом. И наоборот, независимость полученной отражательной способности от расстройки сигнализирует о том, что влияние потерь незначительно. Во-вторых, поскольку разные $\Delta \lambda$ предполагают разные углы падения луча МШГ к торцу волокна то независимость $\mathrm{R}$ от угла хорошо согласуется с предположением о том, что происходит полное внутреннее отражение.

Полученные результаты можно использовать в устройствах на основе аксиальных МШГ резонаторов для управления свойствами мод.

Работа выполнена при финансовой поддержке Российского научного фонда (грант РНФ 18-72-10053).

\section{Литература}

[1] Sumetsky, M. and Fini, J. M., Opt. Express 19(27), 26470 (2011)

[2] D. Kudashkin, I. Vatnik et al., Proc. SPIE. 11355, Micro-Structured and Specialty Optical Fibres VI 